\title{
Sagittal Sinus
}

National Cancer Institute

\section{Source}

National Cancer Institute. Sagittal Sinus. NCI Thesaurus. Code C12513.

A space between the endosteal and meningeal layer of the dura mater, which traverses through the midline along the superior and inferior borders of the falx cerebri, ultimately dividing into two parts: the superior and inferior sagittal sinus. 